\title{
Evaluation on the receptor-binding preference and drug resistance of H9N2 influenza viruses
}

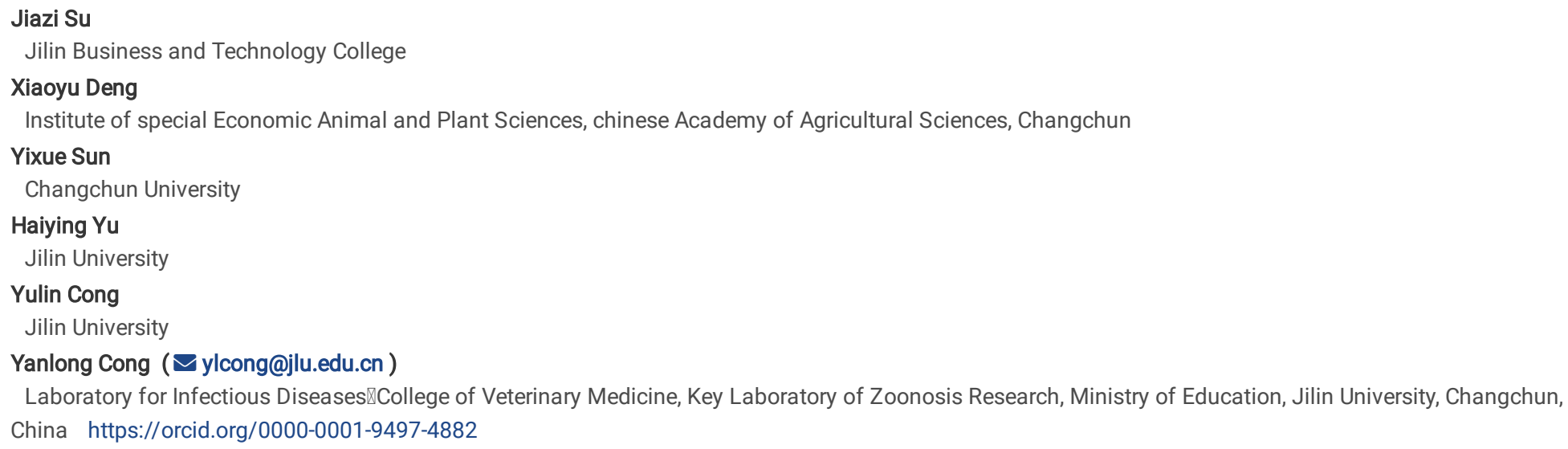

\section{Research Article}

Keywords: H9N2, influenza virus, receptor-binding preference, drug resistance

Posted Date: April 21st, 2021

DOI: https://doi.org/10.21203/rs.3.rs-398041/v1

License: (c) (1) This work is licensed under a Creative Commons Attribution 4.0 International License. Read Full License 


\section{Abstract}

The enzootic and zoonotic nature of H9N2 avian influenza viruses pose a persistent threat to global poultry industry and human health. This particular subtype influenza virus raises public concerns because it possesses human receptor specificity. In this study, four H9N2 virus strains clustered into the G57like viruses preferentially bound to SAa2,6 receptors as demonstrated in the results from the receptor-binding assay. The molecular dynamic simulation showed that HAQ226L substitution of H9N2 viruses may alter the conformation of the 220-loop of hemagglutinin (HA) and thus optimize the contacts between HA and human receptors, thereby increasing the preference for a2,6-linkages. The acquisition of an additional N-glycosylation site at position 264 close to the enzyme active sites of neuraminidase of H9N2 viruses induced the loss of hydrogen bonding between 276E at the enzyme active sites and Zanamivir and further led to occurrence of Zanamivir-resistant of viruses. This study shows the relationship between the conformational changes due to amino acid variations and viral biological phenotypes, which emphasizes the necessity for monitoring the continual evolution of H9N2 viruses and comprehensively assessing their potential zoonotic threat.

\section{1 | Introduction}

Avian influenza virus (AIV) is classified into 16 hemagglutinin (HA) and 9 neuraminidase (NA) subtypes based on antigenic differences [1]. They not only cause serious economic damage to the global poultry industry, but also occasionally pose substantial threats to public health [2]. H9N2 is one of the most widespread subtypes of the AIV family and is found worldwide in wild birds and as an enzootic pathogen in poultry across much of Asia, the Middle East, and North Africa [3]. H9N2 viruses not only infect different types of wild birds and terrestrial poultry, but also evolve to break through the interspecies barrier transmitting to pigs, dogs, horses, mink, pika, and bats [4-6]. Most noteworthily, the long-term prevalence favors the interspecies transmission of H9N2 viruses from avian species to humans $[5,6]$. These findings indicate that H9N2 viruses have gained the capacity to overcome host restriction factors. The enzootic and zoonotic nature of H9N2 viruses is a great source of concern and emphasizes the importance of compressively understanding the fitness of this particular subtype of AIVs.

Although the molecular basis of host-range restrictions is not completely defined, the compatibility between the HA protein of virus and its corresponding receptor, sialic acid (SA), on the host cell is thought to contribute in part to the adaptation of virus to a specific host [5, 7]. The HAs of influenza viruses isolated from avian species typically preferentially bind to SAa2,3 glycans, which represent avian-type receptors. The rise in the ability of HAs to preferentially bind to SAa2,6 glycans, which represent human-type receptors, is proved to be one of the important factors for the human adaptation of AIVs [8]. The receptor-binding property of influenza A viruses depends on the receptor-binding domain (RBD) in the globular head of HA [9]. It has been well demonstrated that residue 226 within the 220-loop RBD is a major determinant of the HA binding preference for either "human-type" or "avian-type" receptors [10] and is thought to be associated with mammalian tropism of AlVs [11-14].

From July 1998 to August 2020, at least 69 people worldwide were infected with H9N2 viruses. Retrospective serosurveys also revealed high seropositivity rates for H9N2 antibodies among poultry workers [5,6]. Once humans are infected with influenza virus, the usage of antiviral drugs is one of the important means to control the progression of the disease. Compared with the M2 inhibitors which have been abandoned, the NA inhibitors may be the only effective drugs available at present. However, these NA inhibitors also face severe challenges because of high variability of NA genes. In view of the questioned efficacy and adverse side effect of Oseltamivir, a NA inhibitor, the World Health Organization had reduced it from a core drug to an adjuvant drug in June 2017. In this case, the inhibitory effect of another NA inhibitor, Zanamivir, on influenza virus needs to be evaluated.

In the phylogenetic tree of HA genes, H9N2 AIVs comprise of two distinctive phylogenetic lineages: North American lineage (A/Turkey/Wisconsin/1/1966-like (Ty66-like)) and Eurasian lineage. Among the Eurasian lineage, it can be further classified into three sublineages: A/Duck/Hong Kong/Y439/1997-like (Y439like), A/Quail/Hong Kong/G1/1997-like (G1-like), and A/Chicken/Beijing/1/1994-like (BJ94-like). Before 2010, the BJ94-like sublineage mainly includes three clades: BJ94-like, A/Duck/Hong Kong/Y280/1997-like (Y280-like), and A/Chicken/Shanghai/F/1998-like (SH98-like). Since 2010, a novel G57-like clade in the BJ94-like sublineage was identified, which was responsible for the H9N2 outbreaks during 2010-2013 and became the most predominant genotype recently [15]. According to the HA phylogenetic tree of human H9N2 viruses registered in the NCBI influenza database (https://www.ncbi.nlm.nih.gov/genomes/FLU/Database/nph-select.cgi?go = database) and the GISAID EpiFlu database (http://platform.gisaid.org), we found that the potential of G57-like AIVs to infect humans was obviously higher than that of other clades of viruses (Fig. 1). Therefore, we evaluated the potential public health threat and drug susceptibility of the G57-like H9N2 viruses in this study.

\section{2 | Methods And Materials}

\section{1 | Viruses}

Four G57-like H9N2 virus strains were analyzed in this study, the HA nucleotide sequences for which are available from GenBank under accession numbers KF886385, KF886393, KF886401, and KF886409. They are A/Chicken/Jilin/DH102/2012 (DH102), A/Chicken/Jilin/DH104/2012 (DH104), A/Chicken/Jilin/DH108/2012 (DH108), and A/Chicken/Jilin/DH109/2012 (DH109). The viral infectivity of each strain was determined by serial titration in 10-day-old specific pathogen free embryonated chicken eggs and was expressed as $50 \%$ of the egg infective dose $\left(E_{50}\right) / \mathrm{mL}$.

\section{2 | Solid-phase direct binding assay}

To directly examine the intrinsic receptor specificity of four H9N2 virus strains, a solid-phase direct binding assay with a streptavidin-biotin detection system was used as described previously [16]. Briefly, the influenza virus particles with a titer of 128 hemagglutination units were adsorbed onto a 96 -well microtiter plate $(100 \mu \mathrm{l} /$ well $)$ at $4^{\circ} \mathrm{C}$ for $16 \mathrm{~h}$. After addition of serial dilutions of receptor analogues against virus particles in the presence of $10 \mu \mathrm{M}$ of $\mathrm{NA}$ inhibitor, 
Zanamivir ( $\mathrm{TCl}$, Japan), the plate was incubated at $4^{\circ} \mathrm{C}$ for $2 \mathrm{~h}$ and then washed with a cold washing solution and incubated with streptavidin conjugated to horseradish peroxidase (HRP-streptavidin) (Sigma-Aldrich, USA) in the working buffer at $4^{\circ} \mathrm{C}$ for $1 \mathrm{~h}$. After washing, $100 \mu \mathrm{l} /$ well of substrate solution ( $0.01 \%$ 3,3',5,5'-Tetramethylbenzidine (Sigma-Aldrich, USA) and 0.004\% hydrogen peroxide in citrate-phosphate buffer [pH 5.0]) was added and the reaction was stopped with $2 \mathrm{M} \mathrm{H}_{2} \mathrm{SO}_{4}$. Optical density was determined at $450 \mathrm{~nm}$ with a Multiscan plate reader (Labsystems, Finland). Four different receptor glycopolymer analogs were used: Biotynilated sialylglycopolymers Neu5Aca2,3Galß1,4Glc-PAA-biotin (3'SL) and Neu5Aca2,6Galß1,4Glc-PAA-biotin (6'SL) were obtained from Glycotech, USA; Neu5Aca2,3GalB1,4GlcNAc-SpNH-PAA-biotin (3'SLN) and Neu5Aca2,6Galß1,4GIcNAc-SpNH-PAA-biotin (6'SLN) were kindly provided by the Consortium for Functional Glycomics (Scripps Research Institute, Department of Molecular Biology, La Jolla, CA). Ten $\mu \mathrm{g} / \mathrm{ml}$ Maackia amurensis agglutinin (MAA) (Sigma-Aldrich, USA) specifically binding to SAa2,3Gal and Sambucus nigra agglutinin (SNA) (Sigma-Aldrich, USA) specifically binding to SAa2,6Gal were used as positive controls of virus. PBS was set up as a negative control.

\section{3 | NA enzymatic inhibition assay}

The sensitivity of viral NA to Zanamivir was evaluated by using the NA enzymatic inhibition assay based on the method of MUNANA [17]. Briefly, diluted virus $\left(10^{6} \mathrm{EID}_{50}\right)$ and Zanamivir $\left(0.001 \mathrm{nM}-1 \mathrm{mM}\right.$ in $33 \mathrm{mM}$ 2-[N-morpholino] ethanesulfonic acid [pH 6.0] containing $\left.4 \mathrm{mM} \mathrm{CaCl}_{2}\right)$ were mixed and incubated for 30 minutes at $37^{\circ} \mathrm{C}$, followed by addition of the substrate (MUNANA) (Sigma-Aldrich, USA). After $1 \mathrm{~h}$ at $37^{\circ} \mathrm{C}$, the reaction was stopped. The relationship between the concentration of Zanamivir and the percentage of inhibition was determined, and $\mathrm{IC}_{50}$ values for NA activity were obtained by extrapolating those findings.

\section{4 | Molecular Simulation}

Utilizing the SWISS-MODEL web-based automated homology-modeling platform (http://swissmodel.expasy.org/) [18], the structural models of HA and NA were constructed. The template structures chosen by SWISS-MODEL are the representative crystal structure of A/Swine/Hong Kong/9/98 (HK98) (H9N2) (PDB ID: 1JSD_A) for HA and A/RI/5+/1957 (H2N2) (PDB ID: 3TIA_A) for NA. The sequence identity between templates and H9N2 virus strains is more than $90 \%$ for HA and above $85 \%$ for NA. The stereochemical quality of the final model was assessed with PROCHECK [19]. The initial model was refined with molecular dynamics (MD) simulation as implemented by the GROMACS4.5.6 package [20] using a GROMOS96 43a1 force field. To obtain the starting structure of the $\mathrm{HA}$ /receptor and NA/drug complex for MD simulation, a standard docking procedure for a rigid protein and a flexible ligand was performed with AutoDock4 [21]. The Lamarckian genetic algorithm (LGA) was applied in the docking calculations. All of the torsional bonds of the receptors or drugs were free to rotate while HA or NA was held rigid. Then the polar hydrogen atoms were added for HA or NA using the AutoDock tools, and Kollman united atom partial charges were assigned [22]. A grid box $(60 \times 60 \times 60)$ with spacing of $0.1 \mathrm{~nm}$ was created and centered on the mass center of the ligand. A total of 100 independent runs were carried out with a maximum of energy evaluations to 25000000 and a population size of 300 . Energy grid maps for all possible ligand atom types were generated using Autogrid 4.2 before performing the docking. The clusters were ranked according to the lowest energy representative in each cluster. Then the receptor or inhibitor docking pose suggesting preferential binding to the HA receptor-binding sites or NA enzyme active sites and the lowest energy conformation in the most populated cluster was chosen for further study [23]. Analysis of the space conformation was performed using PyMol analysis tools.

\section{5 | Statistical analysis}

Statistical analysis was performed using the analysis of variance (ANOVA) method and considered significant when $p<0.05$. Data are shown as means \pm standard deviation (SD).

\section{6 | Ethics statement}

This study was conducted in strict accordance with the recommendations in the Guide for the Care and Use of Laboratory Animals of the Ministry of Science and Technology of the People's Republic of China. The protocols for animal studies were approved by the Committee on the Ethics of Animal Experiments of Jilin University.

\section{3 | Results}

\subsection{Analysis of HA and NA amino acid sequences}

The receptor-binding site (RBS) of HAs and several key sites of NAs of four virus strains compared to those of H9N2 representatives were conducted as shown in Table 1-2. The RBS of the HA1 is involved in the differences in the receptor-binding properties [24]. Previous studies indicated that in the case of H9 HA, a single mutation Q226L might be sufficient to alter its receptor-binding properties [25]. As shown in Table 1, the representatives of Ty66-like, Y439like, BJ94-like, and SH98-like viruses had 226Q, which is characteristic of binding to avian receptors. While those of G1-like, Y280-like viruses and four virus strains in the G57-like clade contained 226L, indicating a preference of binding to human receptors. 
Table 1

Alignment of the HA receptor-binding sites of H9N2 viruses.

\begin{tabular}{|c|c|c|c|c|c|c|c|c|c|c|c|c|c|c|}
\hline \multirow[t]{2}{*}{ Lineages } & \multirow{2}{*}{$\begin{array}{l}\text { Representative } \\
\text { Strains }\end{array}$} & \multirow{2}{*}{$\begin{array}{l}\text { GenBank Accession } \\
\text { No. }\end{array}$} & \multicolumn{12}{|c|}{ Receptor-binding Sites } \\
\hline & & & 98 & 134 & 136 & 153 & 155 & 183 & 190 & 194 & 195 & 225 & 226 & 228 \\
\hline $\begin{array}{l}\text { North } \\
\text { American }\end{array}$ & Ty66 & AF156390 & G & $\mathrm{V}$ & $\mathrm{Y}$ & W & $\mathrm{T}$ & $\mathrm{H}$ & $\mathrm{E}$ & $\mathrm{L}$ & Y & G & Q & G \\
\hline \multirow[t]{9}{*}{ Eurasian } & Y439 & KF188265 & .a & $\cdot$ & $\cdot$ & $\cdot$ & $\cdot$ & $\cdot$ & $\cdot$ & $\cdot$ & $\cdot$ & $\mathrm{D}$ & $\cdot$ & $\cdot$ \\
\hline & $\mathrm{G} 1$ & AF156378 & $\cdot$ & $\cdot$ & $\cdot$ & $\cdot$ & $\cdot$ & $\cdot$ & $\cdot$ & • & • & $\mathrm{D}$ & $\mathrm{L}$ & $\cdot$ \\
\hline & BJ94 & KF188294 & - & - & - & - & - & $\mathrm{N}$ & $\mathrm{v}$ & - & - & • & $\cdot$ & • \\
\hline & Y280 & AF156376 & - & - & - & • & - & $\mathrm{N}$ & $\mathrm{T}$ & - & - & - & $\mathrm{L}$ & - \\
\hline & SH98 & AY743216 & • & • & • & • & • & $\mathrm{N}$ & A & • & • & • & • & • \\
\hline & DH102 & KF886385 & - & - & - & - & - & $\mathrm{N}$ & $\mathrm{T}$ & - & - & • & $\mathrm{L}$ & · \\
\hline & DH104 & KF886393 & - & - & - & • & - & $\mathrm{N}$ & V & - & - & • & $\mathrm{L}$ & • \\
\hline & DH108 & KF886401 & - & • & $\cdot$ & • & • & $N$ & V & • & • & $\cdot$ & L & - \\
\hline & DH109 & KF886409 & - & - & - & - & - & $\mathrm{N}$ & $\mathrm{T}$ & - & - & - & $\mathrm{L}$ & - \\
\hline
\end{tabular}

Table 2

Alignment of several NA key sites of H9N2 viruses.

\begin{tabular}{|c|c|c|c|c|c|c|c|c|c|c|c|c|c|c|c|c|}
\hline \multirow[t]{2}{*}{ Lineages } & \multirow{2}{*}{$\begin{array}{l}\text { Representative } \\
\text { Strains }\end{array}$} & \multicolumn{12}{|c|}{ Potential N-glycosylation sites } & \multicolumn{3}{|c|}{ Enzyme active sites } \\
\hline & & 44 & 61 & 69 & 70 & 86 & 146 & 200 & 234 & 264 & 306 & 309 & 402 & $\begin{array}{l}367- \\
372\end{array}$ & $399-404$ & $\begin{array}{l}431- \\
433\end{array}$ \\
\hline $\begin{array}{l}\text { North } \\
\text { American }\end{array}$ & Ty66 & -a & NIT & - & NIT & NWS & NGT & NAT & NGT & - & - & - & NWS & SKDSRS & DSNNWS & PQE \\
\hline \multirow[t]{9}{*}{ Eurasian } & Y439 & - & $\ldots \mathrm{b}$ & NNT & $\cdot \mathrm{T} \cdot$ & $\cdots$ & $\cdots$ & $\cdots$ & $\cdots$ & - & NMT & - & $\cdots$ & $\cdots \cdots$ & $\cdot \mathrm{N} \cdots$ & $\cdots$ \\
\hline & $\mathrm{G} 1$ & - & $\cdots$ & NNT & $\cdot \mathrm{T} \cdot$ & $\cdots$ & $\cdots$ & $\cdots$ & $\cdots$ & - & - & - & - & $\mathrm{K} \cdots \cdots$ & . DIR. & $\cdots$ \\
\hline & BJ94 & - & $\cdots$ & NST & - & $\ldots$ & $\ldots$ & $\cdots$ & $\cdots$ & - & - & - & $\cdots$ & $\mathrm{K} \cdots \cdots$ & $\cdot D \cdots$ & $\cdots$ \\
\hline & Y280 & - & - & NST & - & $\ldots$ & $\ldots$ & $\cdots$ & $\ldots$ & - & - & - & $\ldots$ & KE $\cdots$ & $\cdot D \cdots$ & $\ldots$ \\
\hline & SH98 & - & - & NST & - & $\cdots$ & $\cdots$ & $\cdots$ & $\cdots$ & - & - & - & $\cdots$ & $\mathrm{K} \cdots \cdots$ & $\cdots D \cdots$ & $\cdots$ \\
\hline & DH102 & - & - & NST & - & $\ldots$ & $\ldots$ & $\cdots$ & $\ldots$ & NIS & - & - & - & $\mathrm{KH} \cdots$. & ..DS. & $\ldots$ \\
\hline & DH104 & - & - & NST & - & $\ldots$ & $\ldots$ & $\cdots$ & $\ldots$ & - & - & - & $\ldots$ & KE $\cdots$ & $\cdot \cdot \mathrm{E} \cdots$ & $\ldots$ \\
\hline & DH108 & - & - & NST & - & $\ldots$ & $\ldots$ & $\cdots$ & $\ldots$ & NVS & - & - & - & KS $\cdots$ & $\cdot R \cdot S \cdot \cdot$ & $\cdots$ \\
\hline & DH109 & - & - & NST & - & $\ldots$ & $\ldots$ & $\ldots$ & $\ldots$ & NIS & - & - & - & $\mathrm{KN} \cdots$ & ...S.. & $\ldots$ \\
\hline
\end{tabular}

The major molecular determinants that are known to influence the functional activities of NA are the stalk length, the potential N-glycosylation sites (NGS) and enzyme active sites [26]. The analysis of NGS showed that the majority of H9N2 viruses contained seven conserved potential NGS at positions 61, 69, $86,146,200,234$, and 402 (N2 numbering). Although loss of the potential NGS at position 61 for four virus strains in this study due to amino acid deletions in the stalk region, DH102, DH108 and DH109 possessed an additional NGS at position 264 in the vicinity of enzyme active sites (Table 2). For four virus strains, the enzyme active sites [26] were conserved and there was no substitution associated with resistance to the NA inhibitors.

\section{2 | Receptor-binding specificity}

In the solid-phase binding assay, four virus strains preferred SAa2,6 glycans (6'SL and 6'SLN) to SAa2,3 glycans (3'SL, 3'SLN) ( $p<0.05)$ (Fig. 2). To better understand the mechanism for HA-receptor interactions, the molecular dynamics simulation was applied to explore the binding affinity of the RBS. It showed that there was a stronger free binding-energy between four H9N2 HAs and SAa2,6 glycans than SAa2,3 glycans (Table 3), which was almost identical with the results of solid-phase binding assay. Statistical analysis of the dynamics simulation showed that both SAa2,3 and SAa2,6 glycans preferentially bound to these positions such as 101Y, 139T, 227Q, and 228G of H9 HAs. In addition, SAa2,3 preferred binding to 183N and 225G of HAs, while SAa2,6 worked better with $140 \mathrm{~S}$ and $141 \mathrm{R}$ of HAs. Notably, 226L did not bind to any type of glycans (Fig. 3). 
Table 3

The molecular docking interaction energy $(\mathrm{kcal} / \mathrm{mol})$ of binding between $\mathrm{HA}$ and receptors. The docked conformations of each ligand were ranked into clusters based on the binding energy and the lowestenergy conformations were visually analyzed. Each experiment was repeated 100 times and the mean

\begin{tabular}{|lllll|}
\hline \multicolumn{5}{c|}{ energy values were listed. } \\
\hline Viruses & 3'SL & 6'SL & 3'SLN & 6'SLN \\
& (3HTT) & (4BSE) & (4BSD) & (4BSC) \\
\hline DH102 & -4.88 & -6.07 & -5.13 & -5.63 \\
\hline DH104 & -4.87 & -5.7 & -4.95 & -5.31 \\
\hline DH108 & -4.8 & -5.82 & -4.48 & -7.03 \\
\hline DH109 & -4.92 & -5.52 & -4.76 & -6.01 \\
\hline
\end{tabular}

\section{3 | NA enzymatic activity}

As shown in Table 3, the NAs from DH102, DH108, and DH109 possessed an additional NGS due to an H264N substitution in the vicinity of enzyme active sites. To elucidate the effect of this mutation on the susceptibility to NA inhibitors, the NA enzymatic inhibition assay was performed. It showed that the H264N substitution of DH102, DH108, and DH109 resulted in a 71.23-81.55-fold-lower susceptibility to Zanamivir than that of DH104 (Fig. 4). To reveal the molecular basis of decreased sensitivity mediated by the $\mathrm{H} 264 \mathrm{~N}$ mutation, we also employed the molecular dynamics simulation to assess the binding stability of NA to Zanamivir. It revealed that the conformational changes induced by the additionally increased carbohydrate side chain resulted in higher free binding-energy and lower binding-affinity relationships between NA and Zanamivir, which is consistent with the results of NA enzymatic inhibition assay (Fig. 5 and Table 4).

Table 4

$\mathrm{EID}_{50}$ and $\mathrm{IC}_{50}$ values for $\mathrm{H} 9 \mathrm{~N} 2$ virus strains and the molecular docking interaction energy $(\mathrm{kcal} / \mathrm{mol})$ of binding between NA and Zanamivir.

\begin{tabular}{|llll|}
\hline Viruses & EID $_{\mathbf{5 0}}$ & IC $_{\mathbf{5 0}}$ & Free binding-energy \\
\hline $\mathrm{DH} 102$ & $10^{-8.42}$ & 3.511 & -5.11 \\
\hline $\mathrm{DH} 104$ & $10^{-8.17}$ & 0.05646 & -8.08 \\
\hline $\mathrm{DH} 108$ & $10^{-8.30}$ & 3.378 & -5.48 \\
\hline $\mathrm{DH} 109$ & $10^{-7.8}$ & 3.243 & -6.2 \\
\hline
\end{tabular}

\section{4 | Discussion}

Previous studies showed that unlike $\mathrm{H} 2$ and $\mathrm{H} 3$ subtypes where changes in the receptor-binding preference from avian to human receptors had been associated with at least two mutations Q226L and G228S of HA, it appears that a single Q226L mutation of HA might be sufficient to alter its receptorbinding properties in the case of H9 HAs [25] and the HA226L was associated with transmission of H9N2 in ferrets and deemed as a marker for increased pandemic risk [27]. In this study, the results of the solid-phase binding assay demonstrated that four G57-like H9N2 virus strains with L at position 226 of HAs preferred SAa2,6 glycans (Fig. 2). But it is worthy of noting that the molecular modeling showed that HA226L did not bind to any type of glycans (Fig. 3). Thus, it was further identified by the molecular docking of the receptor-binding properties of A/Swine/Hong Kong/9/1998 (HK98) (HA226L) and mutant HK98 (HA226Q). The results illustrated that both HK98 HA and mutant HK98 HA had dual receptor-binding properties (Fig. 6a, b, d, e). We assume that the HAQ226L substitution may alter the conformation of the 220-loop of HA and thus optimize the contacts between amino acids located at the 220-loop and human receptors, thereby increasing the preference for a2,6-linkages. Additionally, the molecular superposition revealed that the substitution of HAQ226L caused a slight downward shift ( 0.13Å) of the 220-loop of HA, which makes the spatial conformation of HA binding to human receptors more stable (Fig. 6c, f). Therefore, although the HA226L may not directly bind to receptors, it still plays an important role in determining the receptor-binding property of H9N2 viruses. Whatever, this particular influenza subtype has been evolving and acquiring characteristics that raise concerns that it may become more transmissible among humans.

Repeated human infection in different areas of the world has highlighted the importance of the low-pathogenic H9N2 virus about the potential threat. Antiviral drugs against influenza virus represent the first line of defense. Previous studies revealed that the substitutions at the enzyme active sites of NA N2 were resistant to multiple NA inhibitors [28]. In this study, DH102, DH108, and DH109 possessed an additional NGS because of the H264N substitution closed to the enzyme active sites (Table 1). Hence, we explored the effect of an additional sugar chain on the susceptibility to an NA inhibitor, Zanamivir. The molecular modeling demonstrated that the $\mathrm{H} 264 \mathrm{~N}$ mutation induced the loss of hydrogen bonding between $276 \mathrm{E}$ at the enzyme active sites and Zanamivir (Fig. 5). Although this mutation led to a slight conformational change in the binding between NA and Zanamivir, it provided a structural basis for a lower binding affinity and resulted in reduced sensitivity to Zanamivir. Fortunately, these viruses were avian isolates, indicating that this mutation occurred 
sporadically due to antigenic drift during the course of evolution of viruses that prevail among poultry rather than to the selective pressure posed by the drugs.

Compared to H5N1 viruses, however, the research into H9N2 viruses is lagging far behind. The detection of an increasingly large number of H9N2 viruses showing human receptor specificity, combined with the fact of the wide host range [5], underscores the necessity to predict potential H9N2 epidemics in humans and to perform a regular sensitivity screening for the prevalent H9N2 viruses. Most importantly, long-term H9N2 surveillance paired with comprehensive risk-assessment is necessary in order to assess the potential for human infection. In any case, we cannot ignore the role of H9N2 viruses. Targeting H9N2 might stop them from spawning new, deadly viruses in the future.

\section{Declarations}

\section{ACKNOWLEDGEMENTS}

The work was supported by the National Natural Science Foundation of China (31101825, 31772750, 32072893), the Key Project of Scientific Research Planning in Jilin Provincial Department of Education (JJL [2019] No.73), and the Science and Technology Research Project of Jilin Business and Technology College (2015N0.010).

\section{CONFLICT OF INTEREST}

None of the authors of this study has a financial or personal relationship with other people or organizations that could inappropriately influence or bias the content of the article.

\section{References}

1. Tong S, Zhu X, Li Y, Shi M, Zhang J, Bourgeois M, Yang H, Chen X, Recuenco S, Gomez J, Chen LM, Johnson A, Tao Y, Dreyfus C, Yu W, McBride R, Carney PJ, Gilbert AT, Chang J, Guo Z, Davis CT, Paulson JC, Stevens J, Rupprecht CE, Holmes EC, Wilson IA, and Donis RO. New world bats harbor diverse influenza A viruses. PLoS Pathog 2013, 9, e1003657.

2. Lam TT, Wang J, Shen Y, Zhou B, Duan L, Cheung CL, Ma C, Lycett SJ, Leung CY, Chen X, Li L, Hong W, Chai Y, Zhou L, Liang H, Ou Z, Liu Y, Farooqui A, Kelvin DJ, Poon LL, Smith DK, Pybus OG, Leung GM, Shu Y, Webster RG, Webby RJ, Peiris JS, Rambaut A, Zhu H, and Guan Y. The genesis and source of the H7N9 influenza viruses causing human infections in China. Nature 2013, 502, 241-244.

3. Peacock TP, Harvey WT, Sadeyen JR, Reeve R, and Iqbal M. The molecular basis of antigenic variation among A(H9N2) avian influenza viruses. Emerg Microbes Infect 2018, 7, 176.

4. Kandeil A, Gomaa MR, Shehata MM, El Taweel AN, Mahmoud SH, Bagato O, Moatasim Y, Kutkat O, Kayed AS, Dawson P, Qiu X, Bahl J, Webby RJ, Karesh WB, Kayali G, and Ali MA. Isolation and Characterization of a Distinct Influenza A Virus from Egyptian Bats. J Virol $2019,93$.

5. Peacock THP, James J, Sealy JE, and Iqbal M. A Global Perspective on H9N2 Avian Influenza Virus. Viruses $2019,11$.

6. Song W, and Qin K. Human-infecting influenza A (H9N2) virus: A forgotten potential pandemic strain? Zoonoses Public Health 2020, 67, $203-212$.

7. Dou D, Revol R, Ostbye H, Wang H, and Daniels R. Influenza A Virus Cell Entry, Replication, Virion Assembly and Movement. Front Immunol $2018,9,1581$.

8. Shriver Z, Raman R, Viswanathan K, and Sasisekharan R. Context-specific target definition in influenza a virus hemagglutinin-glycan receptor interactions. Chem Biol 2009, 16, 803-814.

9. Pappas C, Yang H, Camey PJ, Pearce MB, Katz JM, Stevens J, and Tumpey TM. Assessment of transmission, pathogenesis and adaptation of H2 subtype influenza viruses in ferrets. Virology 2015, 477, 61-71.

10. Kosik I, Ince WL, Gentles LE, Oler AJ, Kosikova M, Angel M, Magadan JG, Xie H, Brooke CB, and Yewdell JW. Influenza A virus hemagglutinin glycosylation compensates for antibody escape fitness costs. PLoS Pathog 2018, 14, e1006796.

11. Kaverin NV, Rudneva IA, llyushina NA, Lipatov AS, Krauss S, and Webster RG. Structural differences among hemagglutinins of influenza A virus subtypes are reflected in their antigenic architecture: analysis of H9 escape mutants. J Virol 2004, 78, 240-249.

12. Nobusawa $E$, Ishihara $H$, Morishita T, Sato K, and Nakajima K. Change in receptor-binding specificity of recent human influenza A viruses (H3N2): a single amino acid change in hemagglutinin altered its recognition of sialyloligosaccharides. Virology 2000, 278, 587-596.

13. Obadan AO, Santos J, Ferreri L, Thompson AJ, Carnaccini S, Geiger G, Gonzalez Reiche AS, Rajao DS, Paulson JC, and Perez DR. Flexibility In Vitro of Amino Acid 226 in the Receptor-Binding Site of an H9 Subtype Influenza A Virus and Its Effect In Vivo on Virus Replication, Tropism, and Transmission. J Virol 2019, 93.

14. Wan $\mathrm{H}$, and Perez DR. Amino acid 226 in the hemagglutinin of H9N2 influenza viruses determines cell tropism and replication in human airway epithelial cells. J Virol 2007, 81, 5181-5191.

15. Pu J, Wang S, Yin Y, Zhang G, Carter RA, Wang J, Xu G, Sun H, Wang M, Wen C, Wei Y, Wang D, Zhu B, Lemmon G, Jiao Y, Duan S, Wang Q, Du Q, Sun M, Bao J, Sun Y, Zhao J, Zhang H, Wu G, Liu J, and Webster RG. Evolution of the H9N2 influenza genotype that facilitated the genesis of the novel H7N9 virus. Proc Natl Acad Sci U S A 2015, 112, 548-553.

16. Cong Y, Wang G, Guan Z, Chang S, Zhang Q, Yang G, Wang W, Meng Q, Ren W, Wang C, and Ding Z. Reassortant between human-Like H3N2 and avian H5 subtype influenza A viruses in pigs: a potential public health risk. PLoS One 2010, 5, e12591. 
17. Vavricka CJ, Liu Y, Kiyota H, Sriwilaijaroen N, Qi J, Tanaka K, Wu Y, Li Q, Li Y, Yan J, Suzuki Y, and Gao GF. Influenza neuraminidase operates via a nucleophilic mechanism and can be targeted by covalent inhibitors. Nat Commun 2013, 4, 1491.

18. Biasini M, Bienert S, Waterhouse A, Arnold K, Studer G, Schmidt T, Kiefer F, Gallo Cassarino T, Bertoni M, Bordoli L, and Schwede T. SWISS-MODEL: modelling protein tertiary and quaternary structure using evolutionary information. Nucleic Acids Res 2014, 42, W252-258.

19. Tamura K, Stecher G, Peterson D, Filipski A, and Kumar S. MEGA6: Molecular Evolutionary Genetics Analysis version 6.0. Mol Biol Evol 2013, 30, 27252729.

20. Pronk S, Pall S, Schulz R, Larsson P, Bjelkmar P, Apostolov R, Shirts MR, Smith JC, Kasson PM, van der Spoel D, Hess B, and Lindahl E. GROMACS 4.5: a high-throughput and highly parallel open source molecular simulation toolkit. Bioinformatics 2013, 29, 845-854.

21. Hu R, Barbault F, Maurel F, Delamar M, and Zhang R. Molecular dynamics simulations of 2-amino-6-arylsulphonylbenzonitriles analogues as HIV inhibitors: interaction modes and binding free energies. Chem Biol Drug Des 2010, 76, 518-526.

22. Morris GM, Goodsell DS, Huey R, and Olson AJ. Distributed automated docking of flexible ligands to proteins: parallel applications of AutoDock 2.4. J Comput Aided Mol Des 1996, 10, 293-304

23. Hu R, Barbault F, Delamar M, and Zhang R. Receptor- and ligand-based 3D-QSAR study for a series of non-nucleoside HIV-1 reverse transcriptase inhibitors. Bioorg Med Chem 2009, 17, 2400-2409.

24. Shi Y, Wu Y, Zhang W, Qi J, and Gao GF. Enabling the 'host jump': structural determinants of receptor-binding specificity in influenza A viruses. Nat Rev Microbiol 2014, 12, 822-831.

25. Srinivasan K, Raman R, Jayaraman A, Viswanathan K, and Sasisekharan R. Quantitative characterization of glycan-receptor binding of H9N2 influenza A virus hemagglutinin. PLoS One 2013, 8, e59550.

26. Iqbal M, Yaqub T, Reddy K, and McCauley JW. Novel genotypes of H9N2 influenza A viruses isolated from poultry in Pakistan containing NS genes similar to highly pathogenic H7N3 and H5N1 viruses. PLoS One 2009, 4, e5788.

27. Wan H, Sorrell EM, Song H, Hossain MJ, Ramirez-Nieto G, Monne I, Stevens J, Cattoli G, Capua I, Chen LM, Donis RO, Busch J, Paulson JC, Brockwell C, Webby R, Blanco J, Al-Natour MQ, and Perez DR. Replication and transmission of H9N2 influenza viruses in ferrets: evaluation of pandemic potential. PLoS One 2008, 3, e2923.

28. Wu Y, Bi Y, Vavricka CJ, Sun X, Zhang Y, Gao F, Zhao M, Xiao H, Qin C, He J, Liu W, Yan J, Qi J, and Gao GF. Characterization of two distinct neuraminidases from avian-origin human-infecting H7N9 influenza viruses. Cell Res 2013, 23, 1347-1355.

\section{Figures}






Figure 1

The HA phylogenetic tree of human H9N2 viruses registered in the NCBI influenza database and the GISAID EpiFlu database. The red solid circles represent those H9N2 viruses of human origin. The blue solid triangles indicate those representatives in each clade of H9N2 viruses. 

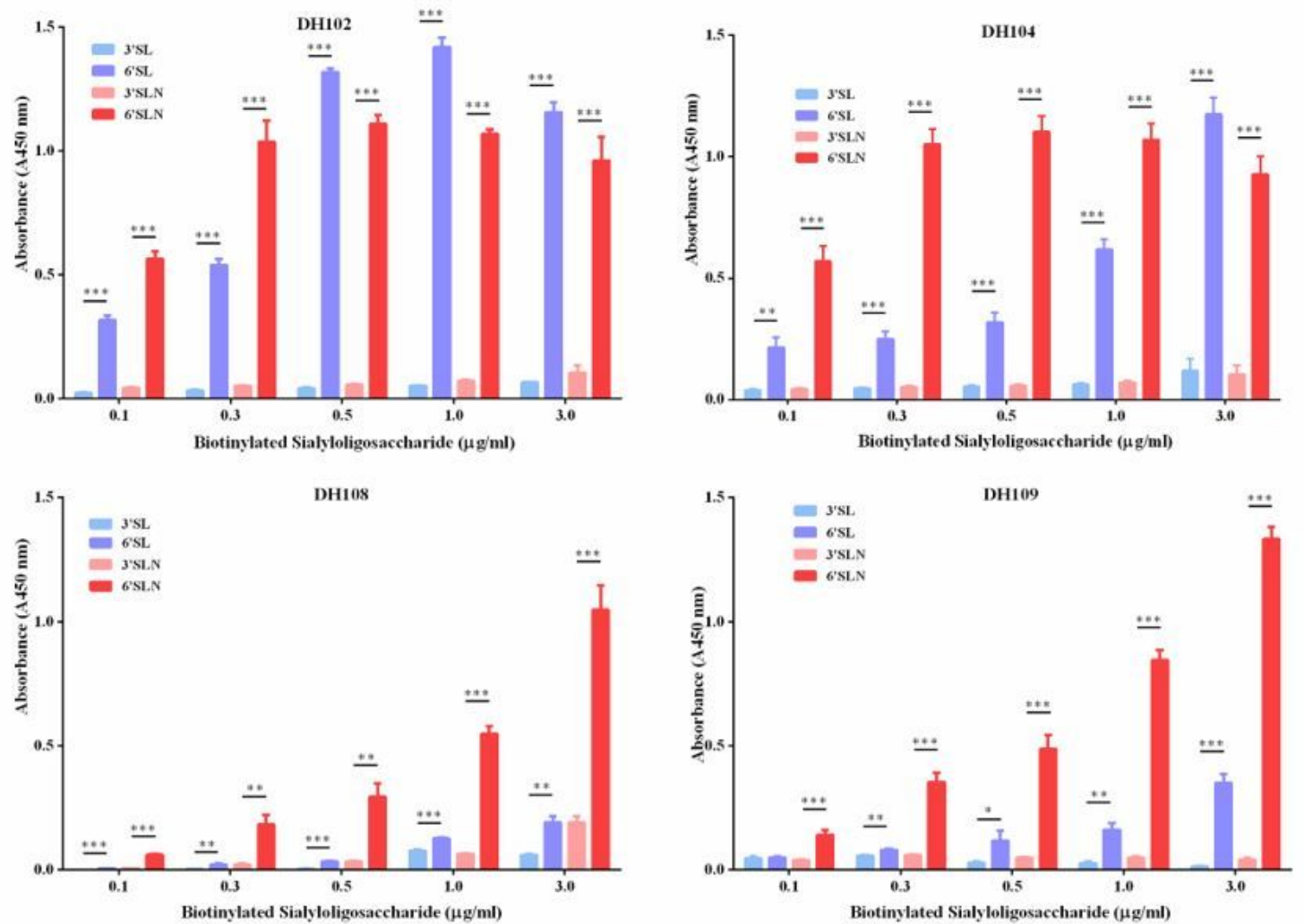

Figure 2

Receptor-binding specificity of H9N2 virus strains determined by the solid-phase direct binding assay. Sialyloligosaccharide bound to virus immobilized in wells of a microtiter plate was detected by HRP-streptavidin as described in the Methods (dependence of absorbance in the wells, A450, versus concentration of polymer). Results represent means \pm SD of triplicate experiments. ${ }^{*}$, $*$ and ${ }^{* *}$ denote $p<0.05, p<0.01$, and $p<0.001$, respectively. 

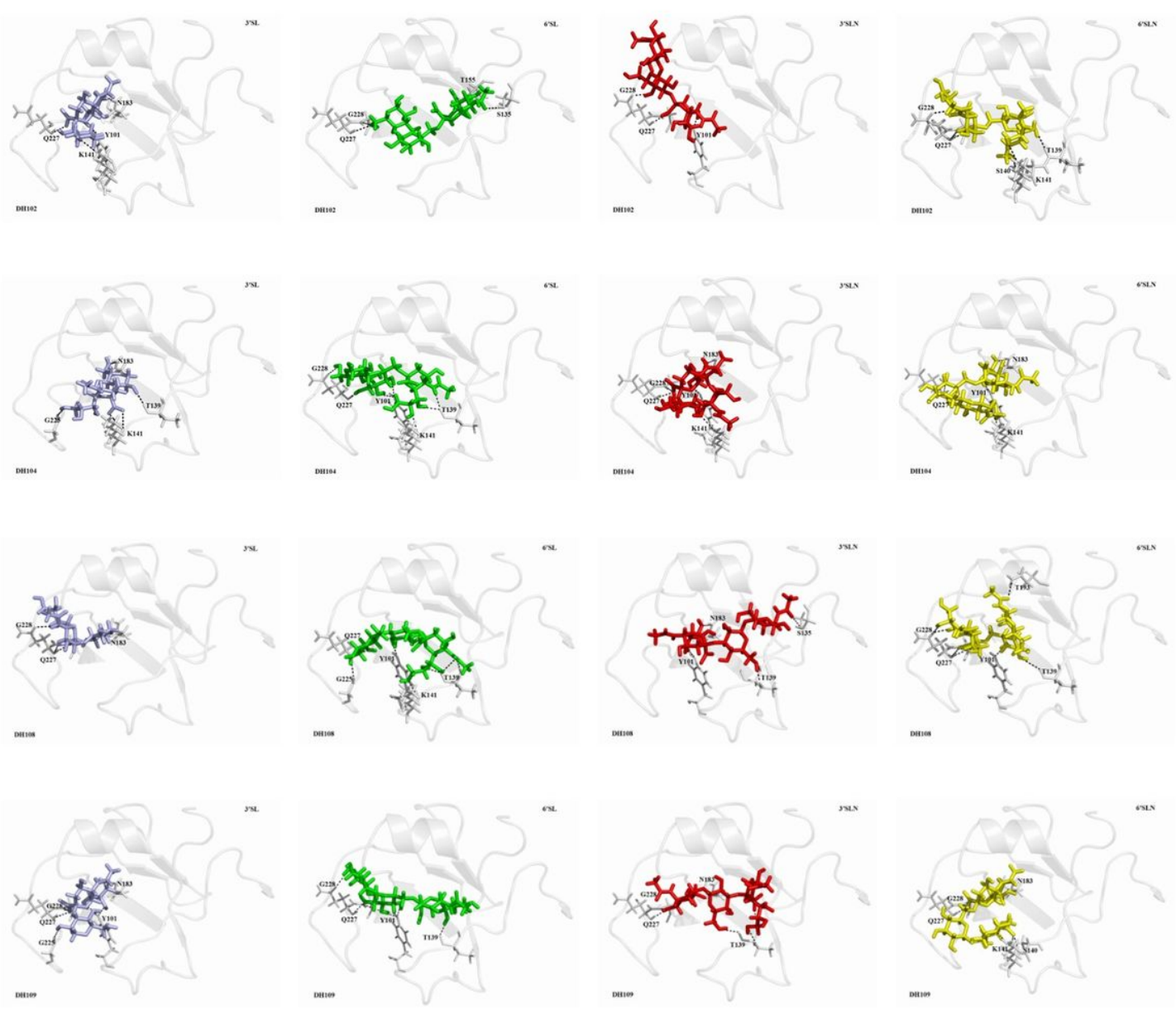

\section{Figure 3}

Structural models of HA-glycan complexes of four H9N2 virus strains. The 3D representations are represented in cartoon and stick, respectively. The binding sites are noted and hydrogen bonds are shown in black. 

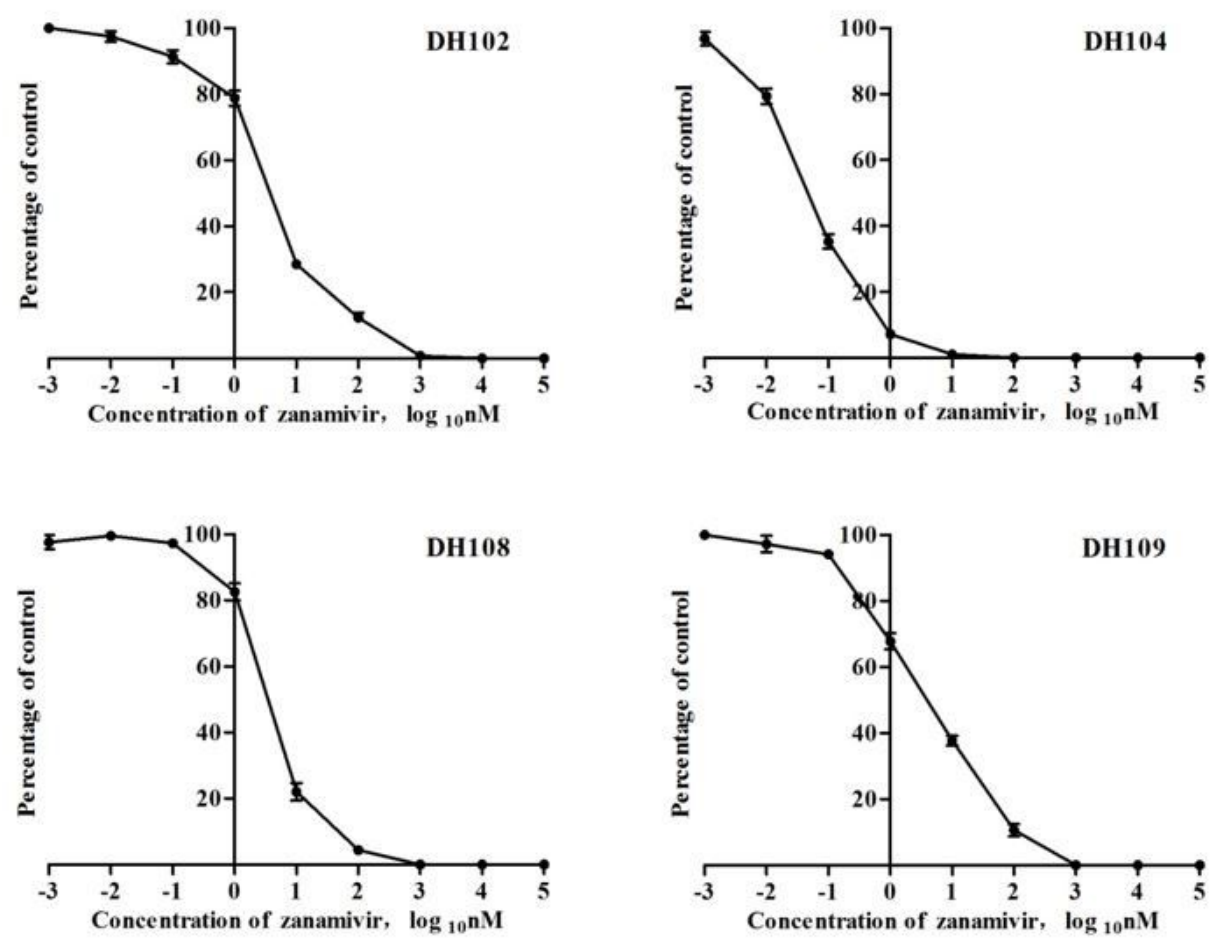

\section{Figure 4}

The susceptibility of H9N2 virus strains to Zanamivir determined by using MUNANA as a substrate. The values represent the means of duplicate experiments.
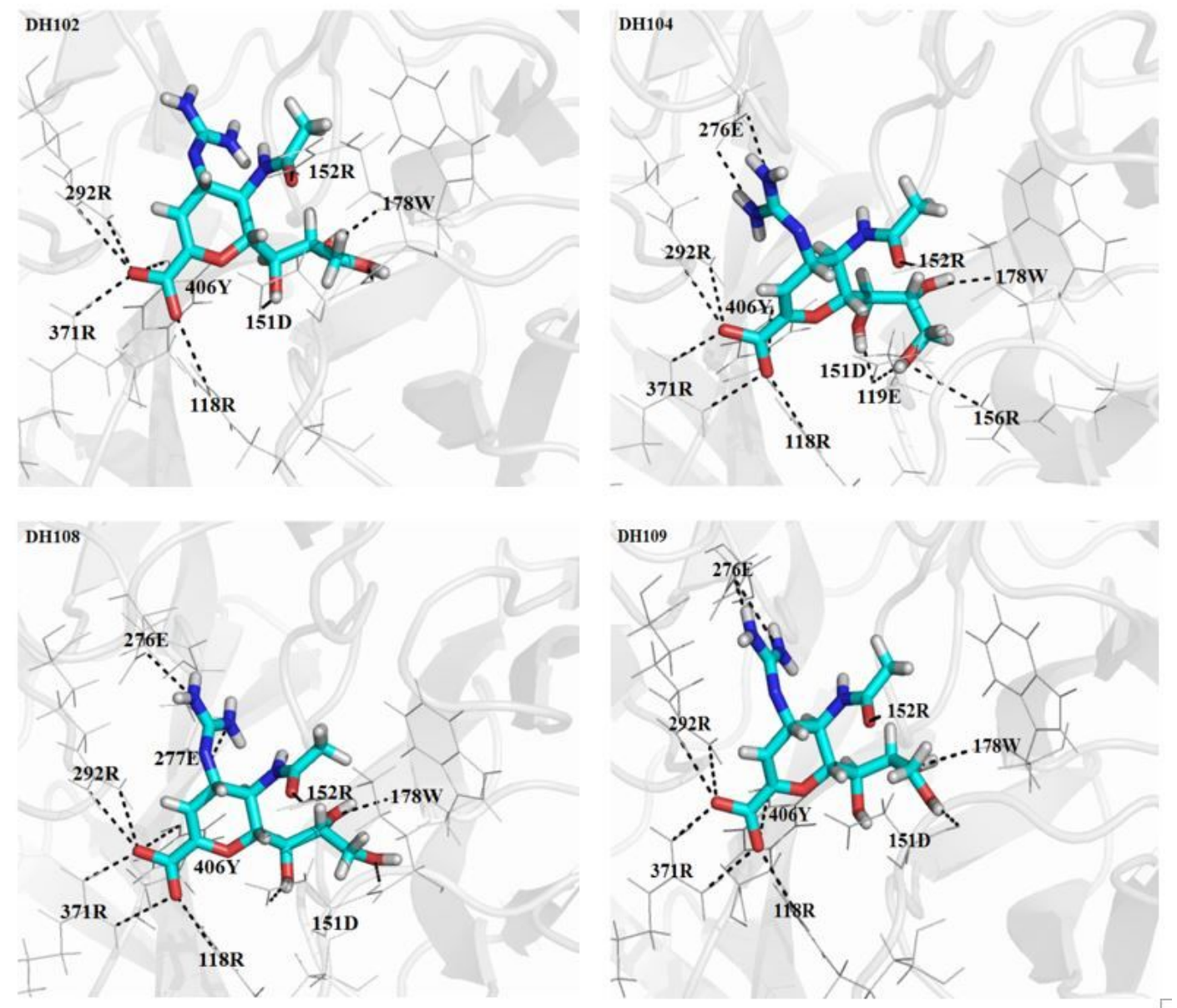
Observed conformational changes in the Zanamivir-binding sites of NA complexes.

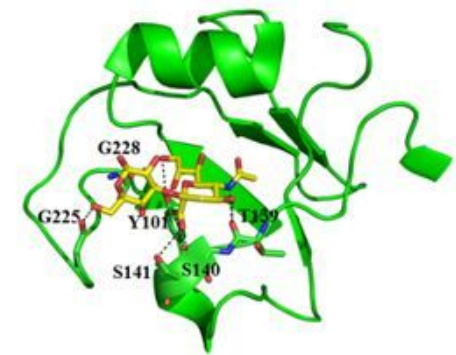

(a) HK98 HA/Avian receptor



(d) HK98 HA /Human receptor

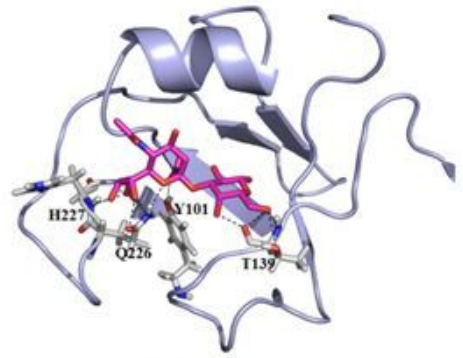

(b) HK98 mutant HA/Avian receptor

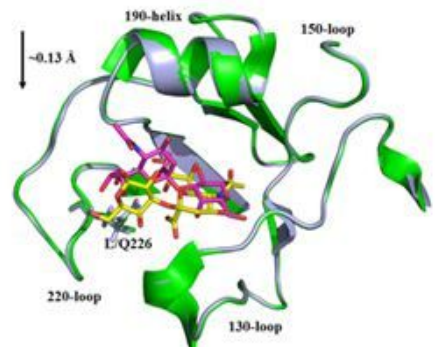

(c) HK98 HA/Avian receptor HK98 mutant HA/Avian receptor

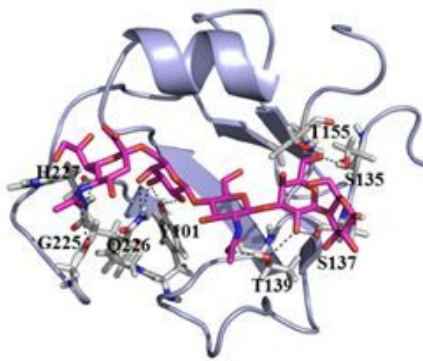

(e) HK98 mutant HA/Human receptor

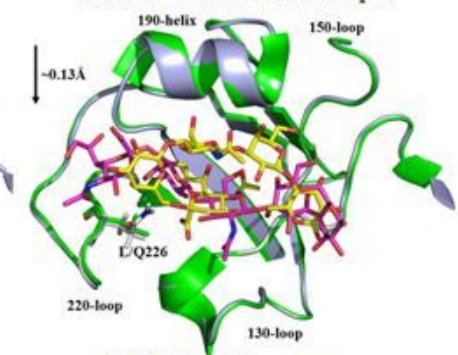

(f) HK98 HA/Human receptor HK98 mutant HA/Human receptor

\section{Figure 6}

Structural comparative analyses of the interactions of the H9N2 HK98 HA and HK98 mutant HA with either avian or human receptor analogs. The three secondary structural elements of the receptor-binding sites (i.e., the 130-loop, 190-helix and 220-loop, H3 numbering) are labeled in ribbon representation, together with the selected residues in stick representation. The hydrogen bonds are shown as dashed lines, HK98 HA is in green, and HK98 mutant HA is in light blue. (a) HK98 HA and (b) HK98 mutant HA with the avian receptor analogs (PDB 1JSH) bound. (c) Structural comparative analysis of the interactions between the HK98 HA/avian receptor and HK98 mutant HA/avian receptor complexes. The glycan receptor sits lower (by 0.13 $\AA$ ) in the HK98 HA complex. (d) HK98 HA and (e) HK98 mutant HA with the human receptor analogs (PDB 1JSI) bound. (f) Structural comparative analysis of the interactions between the HK98 HA/human receptor and HK98 mutant HA/human receptor complexes. The glycan receptor sits lower (by $\sim 0.13 \AA$ ) in the HK98 mutant HA complex. 